\title{
Mobile Assisted Language Learning (MALL) - A Brief Survey
}

\author{
Maaruf Ali ${ }^{1, *}$ and Shayma K. Miraz ${ }^{2}$ \\ ${ }^{1}$ Dept. of Science \& Technology, University of Suffolk, Ipswich, Suffolk, IP4 1QJ, UK \\ maaruf@ieee.org \\ 2International Association of Educators and Researchers (IAER), UK. \\ Khanshayma.123@gmail.com \\ *Correspondence: maaruf@ieee.org
}

Received: 30 $0^{\text {th }}$ January, 2018; Accepted: 28 ${ }^{\text {th }}$ February, 2018; Published: $1^{\text {st }}$ April, 2018

Abstract: This research article presents a brief survey of language learning applications implemented on mobile computing devices, such as cellular mobile phones. The corpus of the literature show the efficacy and effectiveness of using mobile devices to disseminate, train, retain and improve the linguistic ability of non-native speakers.

Keywords: Mobile Assisted Language Learning; MALL; Mobile Learning; e-learning

\section{Introduction}

Mobile-assisted language learning (MALL), is considered one of the most relevant application areas [1-2] to augment the effective process of language acquisition for the non-native speaker. The use of a mobile device, such as a smart phone, helps to make language learning a more immersive experience for the speaker. Immersion using a mobile device is a far cheaper and convenient alternative to actually being able to spend the time in the country where the language is naturally spoken. A significant and ever increasing number of papers are being devoted to second and additional foreign language mobile learning applications [1-7]. The studies show that in particular: vocabulary expansion, retention in long-term memory, pronunciation and grammar skills - are all considerably improved. The studies in particular show that the use of mobile technology to deliver and train different aspects of language learning, though largely explorative, overall support the hypothesis that mobile technology can enhance the learner's second language acquisition skillset [8]. This paper extends the authors' previous work [9] which was presented at the International Conference on eBusiness, eCommerce, eManagement, eLearning and eGovernance (IC5E 2014), held at the University of Greenwich, London, UK, 30-31 July 2014.

\section{Literature Review}

In recent years, there have been many studies and projects using portable and nomadic platform technologies, such as mobile phones or on the $\mathrm{iPod}^{\circledR}$ - for both formal and informal language learning [10-13]. According to most of the above research, the current utilisation of mobile devices in language learning ranges from: vocabulary or grammar learning, to story reading and pronunciation practices. Accordingly, this can be achieved through developing some software applications that require repetition and drills. 
The formal theory of mobile language learning pedagogy is relatively still in its infancy [14] compared to other modes of learning. However, the still rapidly emerging technologies of mobile devices increasingly suggest that the potential they offer to language learning solutions and their portable environments will be highly interactive, ubiquitous and convenient to the user. This is especially the case for those who are not able to attend regular attendance at a venue away from home.

Regarding the above cited studies, it should be noted that the majority of them have focused on the pedagogical aspects of mobile phones in improving language proficiency of different proficiency level language learners. This is without taking into consideration a model for those who want to design targeted audio/visual or print materials to be used for language learning based on mobile phone technology [10].

Mobile phones as new addition to information and communication technologies have created new ways to help learners in the process of foreign language learning. Given the importance of academic vocabularies for university students, this study [15] tried to investigate the effectiveness of SMS (short message service) on Iranian university students' vocabulary learning and retention. To this end, 45 university freshman students with upper intermediate proficiency level were chosen to take part in this study. During 16 weeks of the experiment, the participants of the experimental group $(\mathrm{N}=28)$ were taught 320 headwords from the Academic Word List (Coxhead, 2000) via SMS. During the same period of time the participants of the control group $(\mathrm{N}=17)$ were taught the same words by the use of a standard printed hardcopy dictionary.

At the end, both groups were given a vocabulary test from the Academic Word List, to determine the effectiveness of using the mobile SMS service on their vocabulary learning. The scores of each group were compared employing an independent $t$-test. The result of the t-test showed that both groups had improved in the post-test. Although there was not any significant difference between the groups in the post-test, however, the result of the delayed post-test showed that the use of SMS had a more significant effect on vocabulary retention compared to using the dictionary. The experimental group also outperformed the control group. The study by Alemi et al., [15] can have pedagogical implications for language teachers, in that they can use SMS as an effective way to help their students to retain vocabularies in their long-term memory.

Mobile learning has significant potential to be very influential in developing countries [16]. This is so because of its ubiquitous nature and comparative low cost. The adoption of using the mobile phone system appears to be the most practical way of delivering m-learning (mobile-learning) for the foreseeable future. Mobile learning with its attribute of offering "any -time/-place/-pace learning" offers the potential to conveniently accommodate different modes of language learning for different groups of learners. In this study [17], three different educational environments had been utilised for Iranian language learners. Government employees received continuous refreshment of their language skills in a non-formal mode using a combination of mobile web and short messaging service. Two mobile games had also been designed that served as a platform for performing exercises, completing assignments and for conducting self-study in combination with schools and higher education establishments. These custom tailored mobile application language-learning games had conclusively shown to the researchers that they could effectively motivate the learners using an informal (game playing) setting. The learners developed their knowledge whilst they were engaged in language learning performance in a pleasant virtual world (VR) scenario in order to achieve the proposed goals. The paper [16] concluded that using m-learning within the informal framework of mobile VR game playing learning provided a ubiquitous tool that could powerfully help mature adult learners and younger students in Iran during their continuous lifelong learning.

The TOEIC (Test of English for International Communication) MALL project, reported in this paper [17], explored ways to incorporate experimental MALL practices for improving the students' scores on the TOEIC Listening and Reading Tests with existing compulsory language skill-building courses. This was carried out by developing a new module for one of these courses for first-year university students at Kyoto University of Foreign Studies in Japan. This new module did not consist of conventional teacher-led teaching materials that students would normally study as part of 
their course in conventional lesson assignments or in-class activities. The innovative learning module was utilised by students independently outside of the classroom. The MALL project aimed to transfer the responsibility for taking action to learn from the teacher to the students themselves.

A five-step learning module was designed and implemented by the authors [17] in order to foster an initial form of self-directed study unit in which students made their own decisions about whether to study or not. Then, in the long term the unit was used as a foundation to support the students' gradual transition to a more independent subset of self-study and self-regulated mode of learning. The learning module was used with a Nintendo DSTM mobile device and its software, 'DS More Training' for the TOEIC Listening and Reading Tests. It was hoped that the close match of this device with current student lifestyles would prove it to be a motivating MALL vehicle.

[18] Although mobile phones were developed to allow oral interaction, MALL rarely seems to make use of this affordance, at least in published research. Exceptions are found in the learning and teaching of Irish as a Second Language (ISL), as reported by Clooney \& Keogh [19] in 2007. In the Stanford research, native speakers of the target language (L2) coached learners via mobile phone. This approach was abandoned when scheduling difficulties intervened. A second activity requiring oral interaction was also tested at Stanford University, where learners used their mobile phones to take part in automatic voice-controlled grammar and vocabulary quizzes. Although these were accessible at any time and from any location (provided there was mobile phone network coverage), the activity was abandoned, primarily because of problems with voice recognition software. Although this study promoted oral production, like many other documented MALL activities, it used the mobile device to deliver materials, albeit materials to which the learner could respond rather than receive passively.

The Gaelic Irish language learning study describes the use of mobile phones and iPods to support ISL (International School of Languages) at the secondary level. [19] describes a five-week pilot study whose aim was, “... to facilitate school-based oral assessment and students' self-assessment, increase students' communicative competence and motivate students to learn Irish with the fun and familiar props of a mobile phone and web-chat." [19]. In this instance, everyday tools (mobile phones and iPods) were chosen specifically because of their familiarity to learners. Having logged into a voice response system, learners used their mobile phones to listen to and record their answers to a series of questions on different topics. The answers were saved by the system as '.wav' audio format computer files. The teachers were then able to listen to and mark these responses either online or by downloading the answers in the form of a podcast. The podcast content could then be listened to offline and marked in the teacher's own time and place of convenience. Students could also, moreover, download and listen to podcasts containing model responses of and by the teachers. As well as this, laptops were provided to enable learners to take part in text chat sessions. The aim of this was to offer monitored communication by, and support from teachers. In this case, mobile phones used voice rather than text input to support the formal assessment of the learner [18].

The Praxis learning podcast line [20] is an e-learning platform providing a context-driven, social-based, and software-enhanced website for learning foreign languages. It has recently been working to release mobile language learning features for PDAs (personal digital assistants), smart phones, etc., enabling learners to learn phonetics of a given language in an interactive way using multimedia functions on mobile phones (Microsoft research program).

Comas-Quinn, Mardomingo, and Valentine [21] conducted a pilot study in 2009 to investigate how students who study abroad in Spain construct meaning through informal interaction with the target culture via mobile blogging. The participants shared and reflected on their experiences in the target culture with other peers by uploading curated multimedia content (i.e., pictures, short videos, audio files) they gathered in Spain with their mobile devices. Comas-Quinn et al. [21] concluded that the students' use of mobile blogs promoted interaction and a sense of community in an informal setting. In 2010, Shao [22] explored the applicability of mobile blogging for Chinese students who were new comers to Britain. The findings indicated that the Sino mobile group blog could also help the participants understand more effectively and fully the authentic target culture and everyday 
colloquial language use. Moreover, the mobile blogs could serve as a practical tool even for the prospective and non-peripatetic students in China to build readiness of the target language usage and confidence in being aware of life in the target culture. In 2009, Wishart [23] conducted a small-scale study to investigate the feasibility of using mobile technology for teacher training. The study illustrated the promising result that the use of blogging could be a successful way of encouraging and sharing the teacher trainees' reflections on linguistic teaching.

[24] states that among these iPhone and Android apps (applications) are a good number supporting language learning. There are many apps for language learning of the world covering even ancient dead languages, or for specific languages such as Japanese, French and ESL (English as a Second Language). Many of these apps are of similar kind to those available for some time on phones including flashcard programs, dual language dictionaries, and phrase books. Not all are of the highest quality. In some instances, newer hardware and software have allowed for enhanced functionality. Phrase books, for instance, can now hold rich multimedia content, including video as well as audio and integrate with online sites. Some travel guides such as the Lonely Planet apps feature advanced features such as drag-and-drop trip planners, audio phrase books and even augmented reality, which uses the phone camera views to overlay local site information. Vocabulary development programs have become more sophisticated and powerful.

One MALL application used for studying written and more specifically the art of actual Chinese writing is eStroke. Its primary purpose is to help in learning the stroke order for writing Chinese characters. It also includes an extensive dual-language dictionary, features excellent animations and includes personal library and quizzing functions. Another popular app for Chinese language learning is Pleco, which starts out as a free app but adds functionality through a large number of paid add-ons. These add-ons include such extra features as inclusion of specialized dictionaries, enhanced handwriting recognition and optical character recognition. ChinesePod has a nicely designed app that offers a variety of tools to work with during the lesson podcasts and their vocabulary/phrase manipulation. The app also automatically syncs with the user's current learning status on the app that they are currently engaged with [24].

\section{Limitations and Disadvantages}

As mobile technologies provide many advantages: flexibility, low cost, small size, user-friendliness and off course mobility - researchers are exploring how to use mobile technology effectively to support language learning [25]. However, there are also obvious disadvantages to using mobile devices, such as their small screen size, limited presentation of graphics [26]. Also their dependence on having an online Internet connection via a wide bandwidth and fast cellular network may not always be consistent nor present and hence be subjected to disturbances of many kinds. Despite such shortcomings, Thornton and Houser [27] showed that mobile devices can indeed be effective tools for delivering language learning materials for students.

Although a learning service through mobile devices offers many advantages, it does, however, have its own constraints. These restrictive constraints may be listed as:

- Devices often have a small screen, thus making reading a difficulty on such a screen, especially for those visually impaired;

- Data storage is often restricted by the memory capacity of the device;

- Multimedia limitations are dependant on the device hardware and software capability and also includes the memory storage availability;

- Many of the mobile phones were not designed for educational purposes. That is, it is difficult for the learners to use them for the task given by the teachers to be carried out. This is partly due to the initial design of such devices, and partly due to the non-existence of such developed mobile phones with the appropriate input and output interface, such as handwriting recognition using a stylus.

- However, those devices that are in fact quite appropriate for the specific learning task are often simply too expensive for most of the learners to purchase. 
Thus, teachers should be acutely aware of what kind of tools learners actually have at their disposal and whether the student has the financial means to actually afford them and make appropriate utilisation thereof. The next critical step is then for the teacher to chose and select or adapt the available resources compatible with such tools [28]. The nature of this hardware and software selection it has to be stressed may also vary with the socio-economic geographical conditions that the teacher is operating in. Copyright and political factors may also limit what multimedia and streaming services may also be allowed in a particular country. In an experiment,

The time taken to complete a particular task is also not the same when performed on a mobile device as shown by Stockwell [29]. He concluded by his research study that learners found activities undertaken on a mobile device took longer to complete than on a personal computer (PC). Thus this led some students to prefer the use of their PCs to do their assigned tasks. In that experiment many learners indicated from the outset of the research that they did not intend to use their mobile phones for doing their tasks, simply because of the cost of cellular Internet access, the small screen size of their and the lack of a keypad on their mobile phone [29].

Technology diffusion trend has a direct relationship with the adoption and success of mobile assisted language learning. A lot of intensive research has been conducted on how different aspects of technology diffusion trends, including how factors such as: the cross-cultural usability, the digital divide, children with special needs and so forth has an effect thereupon. In fact, these have a great bearing on the likelihood adoption of mobile assisted language learning too. A study conducted by Miraz et al. [30-31] demonstrates the cultural, economic and societal impacts on the users' behaviour and mobile broadband adoption trends. The survey cohort included users from Bangladesh and the United Kingdom and explains how the digital divide can affect general technology adoption, including in particular the utilisation of mobile phones. 'Mobile Academy' [32], a culturally independent mobile learning prototype, was developed to demonstrate how this digital divide can be surmounted by the use of adaptive user interfaces. In 2015, Maaruf and Miraz [33] further examined how culture plays a vital rôle in "Diffusion of IT Innovation in World Society" [33]. Another body of research [34-35] considers the interface design issues for multi-lingual users and advocates that the adoption trends highly depend on how well the interfaces are designed for the speakers of a particular language group.

Fakrudeen et al. [36-37] conducted research on improving the mobile usability for visually impaired users that can also enhance the learning experience of special education needs students [38-39]. Bhuiyan [40] conducted research on automated generation of learning materials, including language learning, on handheld devices, for children with special needs and monitoring [41] their learning, developing and developmental needs.

Miraz et al. [42] explored the concept of plasticity of user-interface design to improve mobile learning usability, including the cross-cultural usability [43-45] aspects of e/m-learning.

\section{Conclusion}

The research of many studies showed that use of cellular mobile phones do in fact conclusively offer many advantages over classroom based teaching, such as in delivering a more immersive language learning environment, convenience of use away from the classroom/lecture hall environment and synchronized with the individual learner paced self-study.

Also the result of the delayed post-test showed that using SMS delivery had a more significant effect on vocabulary retention compared to using a printed classroom based dictionary mode of learning.

The research also identified that there is still much scope for improvement and refinement in offering more suited software for mobile assisted language learning (MALL), such as formatting content to the smaller dimension screen size and the sound capability of the device and input character recognition. However improvements in hardware continue to meet these challenges including greater memory storage, larger screen sizes and have considerably narrowed the gap with desktop based personal computers. 
MALL thus continues to thrive and prosper offering more and more languages including historical and even dead languages over many devices and operating systems.

MALL continues to experience accelerated growth and global market penetration because of its portability, interactivity, connectivity, customisability with the needs of the learner and its ability to deal with the real-time fluid context-sensitive nature of language learning.

\section{References}

[1] Chih-Kai Chang and Ching-Kun Hsu, "A mobile-assisted synchronously collaborative translation-annotation system for English as a foreign language (EFL) reading comprehension”, Computer Assisted Language Learning, vol. 24, no. 2, pp. 155-180, 2011.

[2] Tim de Jong, Marcus Specht, and Rob Koper, “A Study of Contextualised Mobile Information Delivery for Language Learning”, Educational Technology \& Society, vol. 13, no. 3, pp. 110-125, 2010. Available: http://www.ifets.info/journals/13 3/11.pdf

[3] Nicolas A. Gromik, “Cell phone video recording feature as a language learning tool: A case study”, Computers \& Education, vol. 58, no. 1, pp. 223-230, January 2012.

[4] M. Lu, "Effectiveness of vocabulary learning via mobile phone”, Journal of Computer Assisted Learning, vol. 24 , no. 6, pp. 515-525, December 2008.

[5] Claire Kennedy and Mike Levy, “L’italiano al telefonino: Using SMS to support beginners' language learning”, ReCALL, vol. 20, no. 3, pp. 315-330, September 2008.

[6] Patricia Thornton and Chris Houser, “Using mobile phones in English education in Japan”, Journal of Computer Assisted Learning, vol. 21, no. 3, pp. 217-228, June 2005.

[7] Mengmeng Li; Hiroaki Ogata; Bin Hou; Satoshi Hashimoto; Noriko Uosaki; Yuqin Liu and Yoneo Yano, “Development of Adaptive Vocabulary Learning via Mobile Phone E-mail”, Proc. of the $20106^{\text {th }}$ IEEE Int. Conf. on Wireless, Mobile, and Ubiquitous Technologies in Education (WMUTE '10), Kaohsiung, Taiwan, 12-16 April 2010, pp. 34-41. Available: http://ieeexplore.ieee.org/xpl/articleDetails.jsp?arnumber=5476535

[8] Olga Viberg and Åke Grönlund, “Mobile Assisted Language Learning: A Literature Review”, Proc. of the $11^{\text {th }}$ Int. Conf. on Mobile and Contextual Learning 2012, vol. 955, Helsinki, Finland, 16 -18 October, 2012, pp. 9-16, Available: http://ceur-ws.org/Vol-955/papers/paper_8.pdf

[9] Shayma K. Miraz, Maaruf Ali, "An Overview of Mobile Assisted Language Learning (MALL)” in the proceedings of the International Conference on eBusiness, eCommerce, eManagement, eLearning and eGovernance (IC5E 2014), held at University of Greenwich, London, UK， 30-31 July 2014, ISBN-13: 978-81-925233-2-3, pp. 67-70, Available: http://edlib.asdf.res.in/2014/ic5e/ic5e2014010.pdf.

[10] Taher Bahrani, “Mobile Phones: Just a Phone or a Language Learning Device? Cross-Cultural Communication”, 7(2), pp. 244-248, June 13, 2011. Available: http://dx.doi.org/10.3968/j.ccc.1923670020110702.028

[11] G.M. Chinnery, “Emerging technologies. Going to the mall: mobile assisted language learning”. Language Learning \& Technology, 10(1), pp. 9-16, 2006.

[12] V. Kadyte, “Learning can happen anywhere: a mobile system for language learning”, in J. Attewell, G. Da Bormida, M. Sharples, \& C. Savill-Smith (Eds.), 2003.

[13] P.J. Kiernan and K. Aizawa, “Cell phones in task based learning: Are cell phones useful language learning tools?”, ReCALL, 16(1), pp. 71-84, 2004.

[14] S. Joseph and M. Uther, "Mobile language learning with multimedia and multi-modal interfaces", Proc. of the $4^{\text {th }}$ IEEE Int. Workshop on Wireless, Mobile and Ubiquitous Technology in Education. (ICHIT ’06), 2006. 
[15] Minoo Alemi, Mohammad Reza Anani Sarab and Zahra Lari, “Successful Learning of Academic Word List via MALL: Mobile Assisted Language Learning”, International Education Studies, 5(6), ISSN 1913-9020 E-ISSN 1913-9039, September 2012. Available: http://dx.doi.org/10.5539/ies.v5n6p99

[16] F. Fotouhi-Ghazvini, R. A. Earnshaw and L. Haji-Esmaeili, "Mobile Assisted Language Learning in a Developing Country Context”, Proc. of IEEE Int. Conf. on CyberWorlds (2009), Bradford, UK, pp. 391 - 397, September 2009. Available: http://dx.doi.org/10.1109/CW.2009.28

[17] Mutsumi Kondo, Yasushige Ishikawa, Craig Smith, Kishio Sakamoto, Hidenori Shimomura and Norihisa Wada, "Mobile Assisted Language Learning in university EFL courses in Japan: developing attitudes and skills for self-regulated learning”, ReCALL 24(2), pp. 169-187, 2012.

[18] Agnes Kukulska-Hulme and Lesley Shield, “An overview of mobile assisted language learning: From content delivery to supported collaboration and interaction”, ReCALL, 20(3), September 2008, pp 271 - 289. Available: http://dx.doi.org/10.1017/S0958344008000335

[19] G. Cooney and K. Keogh, “Use of mobile phones for language learning and assessment for learning”, Paper presented at MLearn 2007.

[20] Tayebeh Mosavi Miangah and Amin Nezarat, "Mobile-Assisted Language Learning”, Int. J. of Distributed and Parallel Systems (IJDPS,) 3(1), January 2012. Available: http://dx.doi.org/10.5121/ijdps.2012.3126.

[21] A. Comas-Quinn, R. Mardomingo and C.Valentine, "Mobile blogs in language learning: Making the most of informal and situated learning opportunities”, ReCALL, 21(1), pp. 96-112, 2009.

[22] Y. Shao, "Mobile group blogging in learning: a case study of supporting cultural transition”. University of Nottingham, 2010.

[23] J. Wishart, “Use of mobile technology for teacher training”. In M. Ally (Ed.), Mobile Learning: Transforming the Delivery of Education and Training, pp. 265-278, Edmonton, Canada: Athabasca University Press, 2009.

[24] Robert Godwin-Jones, “Emerging Technologies: Mobile Apps For Language Learning”, Language Learning \& Technology, 15(2), pp. 2-11, June 2011. Available: http://1lt.n1su.edu/i ssues june20 l l/e1nerging.pdf.

[25] Yueh-Min Huang, Yong-Ming Huang, Shu-Hsien Huang, and Yen-Ting Lin, “A ubiquitous English vocabulary learning system: Evidence of active/passive attitudes vs. usefulness/ease-of-use”, Computers \& Education, vol. 58, no. 1, pp. 273-282, January 2012.

[26] Michael Albers and Loel Kim, "Information Design for the Small-screen Interface: An Overview of Web Design Issues for Personal Digital Assistants”, Technical Communication, vol. 49, no. 1, pp. 45-60, February 2002. Available: http://www.ingentaconnect.com/content/stc/tc/2002/00000049/00000001/art00005.

[27] Patricia Thornton and Chris Houser, “Using mobile phones in English education in Japan”, J. of Computer Assisted Learning, vol. 21, no. 3, pp. 217-228, June 2005.

[28] A. Kukulska-Hulme, “Will mobile learning change language learning?”, ReCALL 21(2), pp. 157-165, 2009.

[29] G. Stockwell, “Investigating learner preparedness for and usage patterns of mobile learning”, ReCALL, 20(3), pp. 253270, 2008.

[30] Mahdi H. Miraz, Peter S. Excell and Maaruf Ali, “Cultural, Economic and Societal Impacts on Users’ Behaviour and Mobile Broadband Adoption Trends”, Annals of Emerging Technologies in Computing (AETiC), Print ISSN: 2516-0281, Online ISSN: 2516-029X, Vol. 1, No. 1, October 2017, pp. 34-44, published by the International Association of Educators and Researchers (IAER), Available: http://aetic.theiaer.org/archive/v1n1/p5.html.

[31] Mahdi H. Miraz, Monir Bhuiyan and Md. Emran Hossain, "Impacts of Culture and Socio-economic Circumstances on Users’ Behaviour and Mobile Broadband Technology Diffusion Trends”, Proc. of the $4^{\text {th }}$ Int. Conf. on Internet Technologies and Applications (ITA 11) held at the Centre for Applied Internet Research (CAIR), Glyndŵr University 
in Wrexham, North East Wales, UK, 6-9 September 2011, ISBN-10: 0946881685, ISBN-13: 978-0946881680, pp. 473-479, Available: https://arxiv.org/ftp/arxiv/papers/1708/1708.02798.pdf.

[32] Mahdi H. Miraz, Sajid Khan, Moniruzzaman Bhuiyan and Peter Excell, "Mobile Academy: A Ubiquitous Mobile Learning (mLearning) Platform”, Proc. of the Int. Conf. on eBusiness, eCommerce, eManagement, eLearning and eGovernance (IC5E 2014), held at the University of Greenwich, London, UK, 30-31 July, 2014, ISBN-10: 81-925233-2-2, $\quad$ ISBN-13: $\quad$ 978-81-925233-2-3, $\quad$ pp. 89-95, https://arxiv.org/ftp/arxiv/papers/1708/1708.04655.pdf.

[33] Maaruf Ali and *Mahdi H. Miraz, “The Cultural Impact of Diffusion of IT Innovation in World Society”, Proc. of the Int. Conf. on Recent Advances in Computer Systems (RACS-2015), held at University of Ha’il, Ha'il, KSA, DOI: 10.2991/racs-15.2016.19, ISBN: 978-94-6252-146-9, ISSN: 2352-538x, 30 November -1 December 2015, Published by Atlantis Press, Available: https://www.atlantis-press.com/proceedings/racs-15/25847792.

[34] Mahdi H. Miraz, Peter Excell and Maaruf Ali, “User Interface (UI) Design Issues for the Multilingual Users: A Case Study”, Int. J of Universal Access in the Information Society, Print ISSN: 1615-5289, E- ISSN: 1615-5297, August 2016, Vol. 15, No. 3, pp 431-444, Published by Springer-Verlag, DOI: 10.1007/s10209-014-0397-5, Available: https://arxiv.org/ftp/arxiv/papers/1709/1709.02737.pdf.

[35] Mahdi H. Miraz, Maaruf Ali and Peter Excell, "Multilingual Website Usability Analysis Based on an International User Survey”, Proc. of the $5^{\text {th }}$ Int. Conf. on Internet Technologies and Applications (ITA 13) held at Glyndŵr University in Wrexham, North East Wales, UK, 10-13 September 2013, ISBN-10: 0-946881-81-2, ISBN-13: 978-0-946881-81-9, pp. 236-244, Available: https://arxiv.org/ftp/arxiv/papers/1708/1708.05085.pdf.

[36] Mohammed Fakrudeen, Sufian Yousef, Mahdi H. Miraz and AbdelRahman H. Hussein, "Finger Based Techniques for Nonvisual Touchscreen Text Entry”, IAENG Trans. on Engineering Sciences, Print ISBN: 978-981-4667-35-7, Online ISBN: 978-981-4667-37-1, Chapter 28, pp. 372-386, DOI: 10.1142/9789814667364_0028, published by World Scientific, Available: https://arxiv.org/ftp/arxiv/papers/1710/1710.03088.pdf .

[37] Mohammed Fakrudeen, Sufian Yousef and Mahdi H. Miraz, "Finger Based Technique (FBT): An Innovative System for Improved Usability for the Blind Users’ Dynamic Interaction with Mobile Touch Screen Devices”, Proc. of the World Congress on Engineering (WCE 2014), held at Imperial College, London, UK, 2-4 July 2014, ISBN-13: 978-988-19252-7-5, Print ISSN: 2078-0958, Online ISSN: 2078-0966, Vol. 1, pp. 128-132, Available: https://arxiv.org/ftp/arxiv/papers/1708/1708.05073.pdf.

[38] Mukhtar M. Rana, Mohammad Fakrudeen, Mahdi H. Miraz, Sufian Yousef and Alshammari Abderrahman Torqi, "Information and Communication Technology (ICT) and Special Education System in the Kingdom of Saudi Arabia: A Case Study”, Proc. of The HCI International 2011 Conf. held at Hilton Orlando Bonnet Creek, Orlando, Florida, USA, 9-14 July 2011, vol. 174, Print ISBN: 978-3-642-22094-4, Online ISBN: 978-3-642-22095-1, Series ISSN: 1865-0929, Publisher: Springer Berlin Heidelberg, pp. 534-538, DOI: 10.1007/978-3-642-22095-1_107, Available: https://link.springer.com/chapter/10.1007\%2F978-3-642-22095-1_107.

[39] Mohammed Fakrudeen, Mahdi H. Miraz and Peter Excell, "Success Criteria for Implementing Technology in Special Education: a Case Study”, Proc. of the $5^{\text {th }}$ Int. Conf. on Internet Technologies and Applications (ITA 13), held at the Creative and Applied Research for the Digital Society (CARDS), Glyndŵr University in Wrexham, North East Wales, UK, 10-13 September 2013, ISBN-10: 0-946881-81-2, ISBN-13: 978-0-946881-81-9, pp. 226-235, Available: https://arxiv.org/ftp/arxiv/papers/1708/1708.09404.pdf.

[40] Monir Bhuiyan, Mahdi H. Miraz and Likhon Banik, “Automated Generation of Learning Materials for Children with Special Needs in Converged Platforms Using Android”, (Invited Paper), Advanced and Applied Convergence Letters (AACL): Advanced and Applied Convergence and Advanced Culture Technology, ISSN: 2288-6060, vol. 3, pp. 
246-249, published by The Institute of Internet, Broadcasting and Communication, Jeju Island, Korea, 13 November 2014.

[41] Moniruzzaman Bhuiyan, Ambreen Zaman and Mahdi H. Miraz, "Usability Evaluation of a Mobile Application in Extraordinary Environment for Extraordinary People”, Proc. of the Int. Conf. on eBusiness, eCommerce, eManagement, eLearning and eGovernance (IC5E 2014), held at the University of Greenwich, London, UK, 30-31 July, 2014, ISBN-10: 81-925233-2-2, ISBN-13: 978-81-925233-2-3, pp. 96-103, DOI: 10.978.819252/12226, Available: https://arxiv.org/ftp/arxiv/papers/1708/1708.04653.pdf.

[42] Mahdi H. Miraz, Peter Excell, Maaruf Ali and Rich Picking "Cross-Cultural Usability Issues in Web Interaction: Exploration of the Concept of Plasticity of User-Interface Design to Improve M-Learning Usability”, Poster presentation at the $3^{\text {rd }}$ Glyndŵr University \& Staffordshire University Joint Researcher Development Conference held at Staffordshire University, Stoke-on-Trent, UK, 13th July 2015.

[43] Mahdi H. Miraz, Maaruf Ali and Peter Excell, “Design for All: Catering for Culturally Diverse Users”, Int. J. of Computer Science and Information Security (IJCSIS), ISSN: 1947-5500, June 2016, Vol. 14, No. 6, pp 516-524, Pittsburgh, PA, USA.

[44] Mukhtar M. Rana, Mahdi H. Miraz, Mohammed Fakrudeen and Harima Mubeen, "Cross-cultural Information System Issues and Users' Behaviour: A Case Study in the KSA”, Proc. of The $6^{\text {th }}$ IASTED Int. Conf. on Human Computer Interaction (HCI 2011), held at Washington, DC, USA, 16-18 May 2011, ISBN: 978-0-88986-902-8, DOI: 10.2316/P.2011.747-002, Available: https://www.atlantis-press.com/proceedings/racs-15/25847792.

[45] Mahdi H. Miraz, Maaruf Ali and Peter S. Excell, “Cross-cultural Usability Issues in E/M-Learning”, Annals of Emerging Technologies in Computing (AETiC), Print ISSN: 2516-0281, Online ISSN: 2516-029X, Volume 2, No 2, April 2018, pp. 46-55, published by the International Association of Educators and Researchers (IAER), Available: http://aetic.theiaer.org/archive/v2n2/p5.html.

(C) 2018 by the author(s). Published by Annals of Emerging Technologies in Computing (AETiC), under the terms and conditions of the Creative Commons Attribution (CC BY) license which can be accessed at http://creativecommons.org/licenses/by/4.0/. 